\title{
The role of the social work profession in facing the problem of violence against children with disabilities
}

دور مهنة الخدمة الاجتماعية في مواجهة مشكلة العنف ضيد الطفل ذي الإعاقة BY

Prof. Dr. Medhat Mohamed Abo El-Nasr

Head of the Fields Department at the Faculty of Social Work - Helwan University

\author{
Doi: 10.21608/jasht.2021.137043

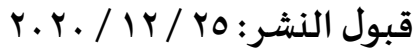

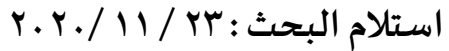

Abstract :

The issue of violence against children has received a lot of attention in all regions of the world, as children are exposed to excessive violence in almost every aspect of their lives. Many efforts have been made and still are being made to confront this serious problem. It is noticeable through some observations, some statistics, and the results of some research studies that the rates of violence directed at a child with a disability are higher than the rates of violence directed at a non-disabled child. Perhaps this may be due to several reasons, which will be explained in the current work paper.The working paper aimed to shed some light on the problem of child violence directed at the child with a disability, in terms of: definition, types, statistics, and factors leading ... The working paper also aimed to clarify the role of the social work profession in facing or confronting this problem. Perhaps clarifying this provides social workers who are working in the field of disability a guide to help them know the professional roles required of them and to perform or exercise these roles. At the end of the working paper, a number of proposals and recommendations were presented that could be used in 
improving the process of effective confrontation of the problem of violence against children in general and violence against children with disabilities in particular.

key words :Violence against children, violence against children with disabilities, social work.

حظيت قضية العنف ضد الأطفال بكل الاهتمام في جميع مناطق العالم حيث

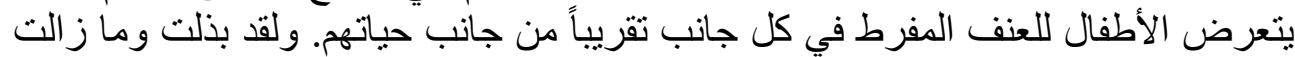

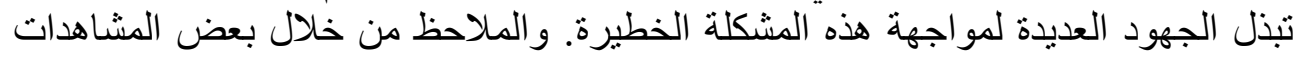

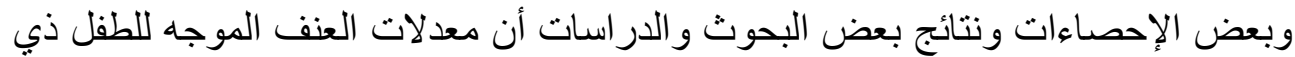

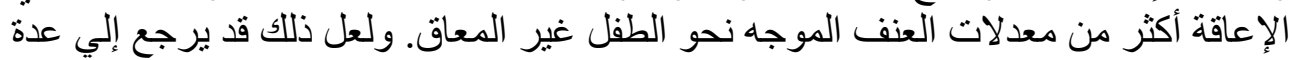

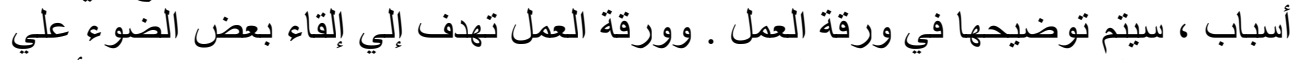

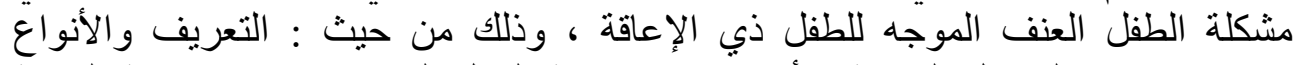

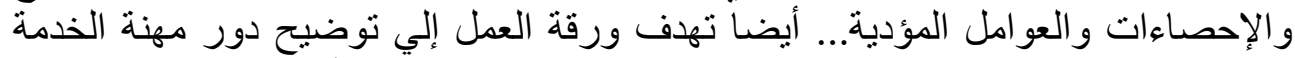

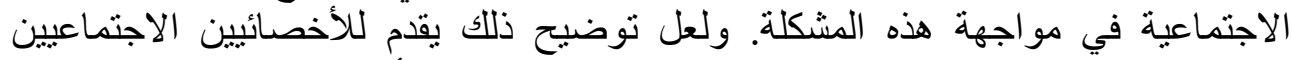

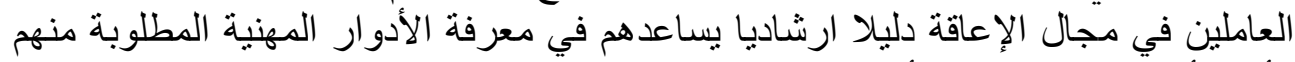

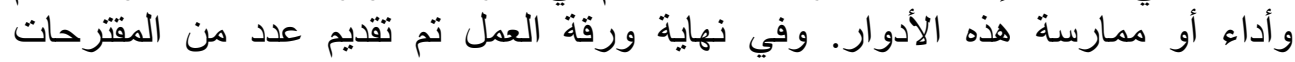

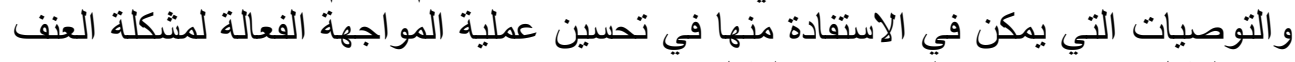

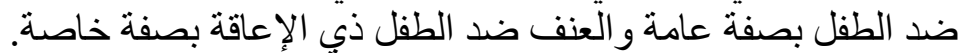
الكلمات المفتاحية : العنف ضد الطفل ، العنف ضد الطف الطفل ذي الإعاقة ، الخدمة الاجتماعية

\section{Introduction :}

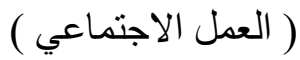

Violence against children has received all attention in all regions of the world as children are exposed to excessive violence in almost every aspect of their lives, which is practiced on them most often by individuals responsible for their protection and safety (such as: a parent, a relative, a servant / the maid, one of the teachers, ....).

Many efforts have been made, and are still being made, to confront this grave problem. Examples of these efforts include conducting scientific research studies to monitor this problem and identify its parties, causes and consequences. Organizing seminars and conferences to discuss this problem from multiple perspectives by professional persons from various professional disciplines; establish 
programs and provide services that work to prevent this problem and treat it in the event it occurs, ...

It is noticeable through some observations, some statistics, and the results of some research studies that the rates of violence directed at a child with a disability are higher than the rates of violence directed at a child without a disability (see for example : Medhat Abo El-Nasr: 2016 , Asma Al-Jaafrawi : 2017 , Mahmoud Radwan : 2018 ).

Perhaps this may be due to several reasons, including: the child's young age, poor physical formation, and sometimes poor mental abilities (in the event that the child has a mental disability), the child's inability to defend himself, his inability to tell others what happened to him, and his fear If he talks about the violence that was practiced against him as a result of the threat exerted by the aggressor, ...

The working paper aims to shed light on the problem of child violence directed at children with disabilities, and to clarify the role of the social work profession in facing this problem. Perhaps clarifying this provides social workers working in the field of disability a guide to help them know the professional roles required of them and to perform or exercise these roles efficiently and effectively.

\section{Definition of violence against children:}

Violence against children, according to the United Nations Secretary-General's Study on Violence against Children (2006), means that the intentional use of physical force or energy, threatened or actual, against any child by any individual or group that leads to or is highly likely to lead to actual harm. Or possible for the child's health, survival, development or dignity.

Also, the World Health Organization (2008: WHO) defines violence directed at children as including all forms of physical, emotional, or sexual abuse or neglect, as well as exploitation and negligence in performing the duty towards the child, whether in actual or potential action, and everything that puts his or her life at risk. And everything 
that negatively affects his growth and his sense of security and reassurance, and everything that affects his dignity and confidence in himself and the society in which he lives.

\section{Types of violence against children:}

There are many types of violence against children, but the following classification is the most common and used in literature and scientific research: The following types of violence against children have been identified:

1- Bodily Abuse

2- Sexual Abuse

3- Emotional abuse

4-Neglect (Medhat Abo El-Nasr : 2020, 45 ).

\section{Statistics of Violence Against Child:}

Unfortunately, we find a dearth of statistics on violence in general, and statistics on violence against children and women in particular. Among the reasons for this are that this violence occurs within the family, and only a small percentage of cases of violence that occur against children and women are reported, and the authorities' lack of interest in this type of violence and considering it as a family matter or an internal issue related to the family and is treated within the family .From the available statistics of violence against children, UNICEF indicated in 2007 that there are 275 million children worldwide who have practiced one or more types of violence. The World Health Organization also estimates that 53\% of child deaths in 2002 were the result of homicide. In Egypt, 65\% of crimes are committed against children, and the percentage of child murders $44 \%$ of annual crimes against children, sexual assault incidents $18 \%$, kidnapping $21 \%$, torture $8 \%$ and beatings $7 \%$ (UNICEF: 2007).

Factors leading to violence against children with disabilities:

We can say that there are many, varied, overlapping and interacting factors together that lead to violence against children (factors related to children / factors related to the child's family / societal and cultural factors). As for the current research topic, the 
following important points can be shed light:

1- At a very young age, the physical weakness of the child and the state of his dependence on the mother or the person concerned with caring for him (such as: the maid or the nanny, one of the relatives ...) is the main door for his exposure to violence.

2- Children's vulnerability to violence is linked to their age, and their capabilities and potential are still developing. Some children are more vulnerable to violence because of their gender, race, ethnicity, disability, or social status.

3- Children with disabilities are at greater risk - than non-disabled children - are at risk of violence for several reasons, ranging from deeply ingrained cultural prejudice against it, and the great emotional, physical, economic and social demands that a child's disability places on his family (Medhat Abo El-Nasr: 2019, 100).

In the United States of America, children with physical, sensory, intellectual or psychological disabilities bear twice the number of violent incidents compared to their non-disabled counterparts. Likewise, the study conducted by the Caribbean Regional Research Office indicated that children with disabilities are highly exposed to all types of violence. Physical / sexual / emotional or emotional / neglect) and most of them are located in the vicinity of the home (Ronald Walton: 2009, 213).

In some areas, children with disabilities are seen as cursed. For example: These children in West and Central Africa are likely to be exposed since their birth to implicit or explicit neglect, and violence can be accepted or even encouraged by the family.

The problem is also that only a small percentage of cases of violence against children are reported and investigated, and few perpetrators are held accountable. Many places in the world also lack systems for recording and studying reports of violence against children. And when there are official statistics based on reports of violence in the home and elsewhere, the statistics are much less than the true magnitude of 
the problem.

At the beginning of this century, the United Nations Committee on the Rights of the Child discussed the issue of violence against children after noting the steady increase in its global prevalence rates, and acknowledging the need for an in-depth international study on the issue of violence against children, and the United Nations SecretaryGeneral appointed a coordinator for the study in February 2003.

The preparation process for the study included regional and country consultations to gather studies, expertise and information, to gain support and encourage networking within the framework of local authorities and civil society. At the level of the Middle East and North Africa region, a regional steering committee was formed to prepare for this study, of which the Arab Council for Childhood and Development was a member, and several consultative meetings were held in Cairo. This study was completed at the end of the year 2006, and the Arabic version was released in June 2007. The study concluded that violence continues against children, and that it represents a major threat to local and global development.

The study also suggested a number of specific recommendations that could lead to the development of strategies aimed at preventing and combating all forms of violence against children and specifies the steps that must be taken at the national and international levels to provide prevention, protection, intervention, treatment, healing and integration for children, as well as forming an advisory board of non-governmental organizations. To follow up this study, it includes 9 international organizations and 9 regional organizations, one of which is the Arab Council for Childhood and Development.

Within the framework of the efforts undertaken by the Arab Council for Childhood and Development ( located in Cairo , Egypt ), it adopted an Arab project aimed at raising attention on the issue of violence against children in all its forms to combat and reduce it through working with media professionals and forming a network of 
Arab media professionals to combat violence against children and organize conferences and seminars on this problem. Including the round table on "Violence directed at the child with a disability" from 10-13 October 2010 in Cairo, in which the researcher participated as an expert on the subject of the table, and in July 2012 a guide was published that represents a summary of the working papers that were presented at this table.

Roles of the social worker in dealing with the problem of a child with a disability who has been subjected to violence:

Disability is a multiple problem in its dimensions and intertwined in its aspects, where the medical aspect is intertwined with social, psychological, educational, rehabilitative and informational, in a way that is difficult to separate between them, so the detection, prediction and control of causes and ills fall within the mission of several sciences and professions in their academic, social and human sense, and the classification processes The assessment and diagnosis of disability and the study of characteristics and means of care and rehabilitation represent a strong challenge to the human sciences (Medhat Abo El-Nasr: 2015, 20).

The team work method has become a necessity for the success of working with the disabled, given their needs for many efforts of specialists from various professional specialties. The problem of disability, like other social problems, is linked to many interwoven factors and variables that require concerted efforts and intensified work in order to confront this problem at the level of prevention and treatment for it (Medhat Abo El-Nasr: 2004, 120).

Also, the process of facing this problem requires the attention and cooperation of many professions, including: the medical profession, the nursing profession, the engineering profession, the education profession and the social work profession, for example. 
As for the social work profession, the International Association of Social Work Schools (IASSW) and the International Federation of Social Workers (IFSW) (2019) provided the following definition:

The social work profession promotes social change, problem solving in human relationships and empowerment and liberation of people to enhance well-being. Utilizing theories of human behavior and social systems, social work intervenes at the points where people interact with their environments. Principles of human rights and social justice are fundamental to social work.

In 2020, the International Association of Social Work Schools (IASSW) and the International Federation of Social Workers (IFSW) developed a global definition for the profession of social work, which is as follows: Social work is a practice-based profession and an academic discipline that promotes social change and development, social cohesion, and the empowerment and liberation of people. Principles of social justice, human rights, collective responsibility and respect for diversities are central to social work. Underpinned by theories of social work, social sciences, humanities and indigenous knowledge, social work engages people and structures to address life challenges and enhance wellbeing. The above definition may be amplified at national and/or regional levels.

The current working paper aims to shed light on the role of the social work profession in facing the problem of violence against children with disabilities, by defining a set of professional roles that social workers working in the field of caring for persons with disabilities must know and practice, in a way that contributes to confronting the problem of violence, against the child (at the level of prevention and treatment) in general, and the problem of violence against children with disabilities in particular.

Knowing that all these professional roles that will be presented later, the social worker cannot perform them alone, and he needs coordination, support and cooperation with his colleagues from other professions working in this field and concerned with the problem of 
the disabled child who has been exposed to violence.

It can be defined the roles of the social worker when dealing with the problem of a child with a disability who has been subjected to violence as follows:

\section{A- The role of the social worker with the disabled child who has} been subjected to violence:

1- Studying the child's problems, know the factors leading to them, and enlighten the child about them.

2- Reducing the child's negative feelings regarding his condition as a disabled person and his circumstances.

3- Reducing the stress of life, study or work for the child.

4- Helping the child to accept his disability and convert his energies towards developing the abilities, organs and senses he has remaining.

5- Helping the child to satisfy his needs, especially social and psychological, and to face his problems, especially personal and social.

6- Helping the child to get along with himself and the surrounding community.

7- Helping the child to benefit from the programs and services of institutions and associations working in the field of care and rehabilitation of the disabled and the field of child care.

8- Helping the child to recognize the meaning, forms, and types of violence and the concept of the dangers that he may face, and to identify the good and bad secrets, to establish the concept of preservation on his body, to distinguish between individuals he can trust and to the aggressors, and to identify mechanisms to protect himself if he feels in danger from others (Known or strangers).

B- The role of the social worker with the family of the disabled child who has been subjected to violence:

1- Helping the child's family to face its problems, especially the 
family, social and psychological problems, which in turn contribute to solving the child's problems.

2- Creating an appropriate, supportive and encouraging family atmosphere that helps the child to deal with his disability appropriately.

3- Involving the family in all stages of the process of helping the child.

4- Educating the family on the methods of proper dealing with the child.

5- Clarify the importance of the family's role in persuading the child of appropriate positive attitudes and behaviors and in modifying inappropriate negative attitudes and behaviors.

6- Emphasizing the role of the family in facing the child's problems and in following up the rehabilitation plans and their success.

7- Providing the family with accurate information about how to care for their child and about the services available in their community.

C - The role of the social worker with groups of children with disabilities who have been subjected to violence:

1- Provide the opportunity for children with disabilities to practice their hobbies through small groups.

2- Using recreation and team play as a treatment method.

3- Providing the opportunity to practice violent games (such as: karate ...) for some children with disabilities as a treatment method to reduce suppression and thwart the aggressive feelings and their increased energies.

4- Helping children with disabilities, through membership in groups,

to form friends and conform to these groups by modifying their negative attitudes and behaviors that are inappropriate to conform with the collective behavior and the culture of the group.

5- Using the group discussion method in clarifying issues and problems, in learning the appropriate social roles, and in acquiring the skills to challenge the disability. 
6- Providing children with disabilities the opportunity to practice social, cultural, artistic, sports and recreational programs ...

D- The role of the social worker with the organization (institution / association):

1- Participating in the management of governmental institutions and NGOs that work in the field of caring and rehabilitation of children with disabilities.

2- Contributing to setting the policy of the institution or association in which he works, taking into account the needs and problems of children with disabilities, and defining its objectives in light of the general policy for the care and rehabilitation of the disabled.

3- Assisting the board of directors of the institution or association in which he works in performing its mission successfully.

4- Contributing to strengthening relationships between employees of the institution or the association and between them and children with disabilities and their families.

5- Cooperating with the work team of the institution or the association in a manner that contributes to the success of the team in performing the tasks required of it.

6- Helping to consolidate and develop the services provided by the institution or association in which he works.

7- Conducting scientific, especially social, research and studies in this field, at the institution or association level.

8- Participation in developing plans and programs concerned with the care and rehabilitation of children with disabilities.

9 - Participation in the implementation of plans and programs concerned with the care and rehabilitation of children with disabilities. 10- Participating in the follow-up, evaluation and evaluation of plans and programs concerned with the care and rehabilitation of children with disabilities.

11- Involving children with disabilities and their families in all previous stages. 
12- Working on discovering volunteers, training them and using them in the service and care of children with disabilities and their families.

E- The role of the social worker with society as a whole:

1- Participation in identifying the needs and problems of children with disabilities and their families, especially social and psychological.

2- Participating in coordinating the efforts of governmental institutions and NGOs working in the field of caring and rehabilitating children with disabilities and their families.

3- Participate in coordinating the efforts of these institutions, societies and other community institutions for the benefit of children with disabilities and their families.

4- Contributing to the organization of conferences, seminars and exhibitions that discuss the needs and problems of children with disabilities, and the conditions of institutions and associations for children with disabilities, and make important recommendations in this regard and deliver them well and effectively to the appropriate officials.

5- Working to spread awareness among citizens about how to deal appropriately with children with disabilities and ways to prevent disability.

6- Preparing booklets and brochures for distribution to schools and other community institutions as a guide to educate students to avoid violence that may be practiced against them.

7-Enlightening public opinion through all means of mass communication and the problems of children with disabilities (including the problem of disability and the problem of violence, for example) in order to correct the wrong attitudes of the masses towards disability and the handicapped child.

8- Participation in conducting scientific research and social studies on issues related to disability in childhood and the problem of violence directed against children with disabilities, care and rehabilitation programs for children with disabilities, and methods of prevention of disability and violence. 
9- The practice of social work in situations of power and struggle in order to defend the rights of children with disabilities as one of the oppressed or underprivileged groups in society in most cases (Robert Barker: 2003, 211).

Social recommendations and proposals to confront the problem of violence against children with disabilities:

In this regard, some social recommendations and suggestions can be made that can contribute to the prevention, reduction or treatment of the problem of violence against children with disabilities, as follows:

1- Increasing awareness-raising campaigns for families on the methods of sound socialization of the rights of children with disabilities and the dangers of violence against them.

2- Increasing awareness campaigns for school pupils on children's rights and how they can acquire prevention skills and deal with the problem of disability and the problem of violence against them

3- Spreading culture and awareness in society about the harms and effects of violence against children, especially through the mass media and places of worship.

4- In the event of violence against children with disabilities, measures must be taken towards early case finding and early intervention by doctors, social workers, psychologists, teachers and police officers, and to treat and deal with them professionally, and in a judicial manner if required.

5- The necessity to train doctors, social workers, psychologists, teachers and police officers on early detection skills and early intervention when violence is detected against a child in general and children with disabilities in particular.

6- The necessity of establishing safe, accessible and well-publicized mechanisms, and at the same time enjoying confidentiality, through which children, their parents, and those concerned with the care and protection of children report cases of disability and 
violence against children. Among these proposed mechanisms are telephone helplines (hotlines) through which to report cases of disability and violence against children.

7- Conducting more scientific research studies on the subject of violence against a child with a disability, provided that the information and results obtained are fed into policies and programs related to the prevention of disability and violence against children or to address these two problems.

8- Preparing guidelines and other training guides on the subject of the problem of violence against children with disabilities, in order to increase the knowledge and understanding of the professional persons working with this group, and contribute to improving their skills when dealing with this problem in terms of prevention and treatment. 


\section{References:}

First: Arabic references

1- Asma Al-Jaafrawi : "The Problem of Violence against Children", Journal of Studies in Social Work, Faculty of Social Work, Helwan University, Cairo: October 2017.

2- Mahmoud Radwan: "The Problem of Abused Children," Journal of Studies in Social Work, Faculty of Social Work, Helwan University, Cairo: January 2018.

3- Medhat Mohammad Abo El-Nasr : Care and Rehabilitation of the Disability Challengers (Cairo: ATRAC Publishing and Distribution, 2004 ).

4- Medhat Mohamed Abo El-Nasr: Disability and the Disabled (Cairo: The Arab Group for Publishing and Distribution, 2009 ).

5- Medhat Mohamed Abo El-Nasr: The Art of Practicing Social Work (Cairo: Dar Al-Fajr for Publishing and Distribution, 2009 ).

6- Medhat Mohamed Abo El-Nasr: "The Role of Social Workers in Confronting the Problem of Violence against the Disabled Child," The Round Table on Violence against Children with Disabilities, The Arab Council for Childhood and Development, Cairo: 10-13 October 2010.

7- Medhat Mohamed Abo El-Nasr: Social Service in the Field of Care for the Disabled (Cairo: Dar Al-Fajr for Publishing and Distribution, 2015).

8- Medhat Mohamed Abo El-Nasr: Social Defense and the Problems of Violence and Crime (Cairo: Faculty of Social Work, Helwan University, 2016 ).

9- Medhat Mohamed Abo El-Nasr: General practice of social service in the field of caring for persons with disabilities (Mansoura: Modern Library for Publishing and Distribution, 2019 ).

10-Medhat Mohamed Abo El-Nasr: The Generalist Practice of Social Work in the Field of Social Defense (Mansoura: Modern Library for Publishing and Distribution, 2020 ). 
11-The Arab Council for Childhood and Development: A Guide in Confronting the Problem of Violence Against the Disabled Child, Cairo: 2012.

Second: Foreign references

1- International Federation of Social Workers \& International Association of Schools of Social Work : Definition of Social Work , 2019.

2- International Federation of Social Workers \& International Association of Schools of Social Work : Global Standards for the Education and Training of the Social Work Profession , 2020.

3- Robert L. Barker: The Social Work Dictionary (Washington, DC : NASW Press , 4 th. ed. , 2003 ) .

4- Ronald Walton: Mainstreaming for Disable Persons (Cardiff, U.K.: Oxford Publishing Co., 2009 ) .

5- UNICEF : Violence Against Children ( N.Y. : The United Nations Children s Fund , 2007 ).

6- United Nations : The United Nations Secretary-General's Study on Violence against Children (2006).

7- WHO : Global Estimates of Health Consequences Due to Violence Against Children ( Geneva : World Health Organization , 2008 ) . 